\title{
Differences between training and game loads in young basketball players
}

\section{Diferenças entre as cargas de treino e jogo em jovens basquetebolistas}

\author{
Fernanda Martins Brandão ${ }^{1}$ \\ (D) https://orcid.org/0000-0003-4489-9372 \\ Dilson Borges Ribeiro Junior ${ }^{1}$ \\ (D) https://orcid.org/0000-0002-4616-1761 \\ Vinícius Figueirôa da Cunha ${ }^{1}$ \\ (iD https://orcid.org/ 0000-0002-6880-9856 \\ Gustavo Bellini Meireles ${ }^{1}$ \\ (D) https://orcid.org/0000-0002-6409-9113 \\ Maurício Gattás Bara Filho \\ (D) https://orcid.org/ 0000-0003-1219-8379
}

Abstract - The same training stimulus can provide different physiological adaptations for athletes of the same team. The aim of this study was to compare training and game loads in young male basketball players. Data were obtained from 4 training sessions and one game session using Polar Team Pro equipment. Physiological data (HR) were used to monitor internal responses through Edwards'TRIMP, and data on distance traveled by the player on the court (External Training Load). To observe differences between eTRIMP, HR max and distance traveled, the T-Test was used for paired samples. The mean internal training load, according to Edwards' TRIMP, for the four training sessions was $132 \pm 69$. Mean HR max and distance traveled values were $143 \pm 67$ and $2.273 \pm 1170$, respectively. Regarding game load, Edwards'TRIMP, maximum HR and distance traveled were $108 \pm 33,199 \pm 4$ and $2.240 \pm 617$, respectively. No statistically significant differences were found between the mean values of training sessions compared to the game session in relation to the Edwards' TRIMP measures and distance traveled, but HR max was significantly higher during the game compared to training. It was concluded that the loads applied during training are similar to those applied in the game.

Key words: Basketball; Monitoring; Youth sports.

Resumo - O mesmo estímulo de treinamento pode proporcionar diferentes adaptaçôes fisiológicas para os atletas de uma mesma equipe. O objetivo deste estudo foi comparar as cargas de treino e jogo em jovens jogadores de basquetebol do sexo masculino. Os dados foram obtidos de 4 sessóes de treinamento e uma sessão de jogo a partir do equipamento Polar Team Pro, sendo mensurados dados fisiológicos $(F C)$, que foram utilizados para monitorar a CIT através do TRIMP de Edwards, e dados sobre a distância percorrida do jogador em quadra (CET). Para observar as diferenças entre o TRIMP, FC máx e distância percorria, foi utilizado o Teste T para amostras pareadas. A média das CIT, de acordo com o TRIMP de Edwards, para as 4 sessôes de treinamento foi $132 \pm 69$. Já a média da FC máxima e da distância percorrida foram $143 \pm 67$ e $2.273 \pm 1170$, respectivamente. Em relação a carga de jogo, o TRIMP de Edwards, a FC máxima e a distância percorrida foram de $108 \pm 33$, $199 \pm 4$ e $2.240 \pm 617$, respectivamente. Não foram encontradas diferenças estatisticamente significativas entre a média das sessões de treino em comparação com a sessão do jogo em relação as medidas de TRIMP de Edwards e distância percorrida, porém a FC máxima foi significativamente maior durante a partida em comparação com o treinamento. Conclui-se que, a aplicação das cargas da equipe investigada durante os treinamentos é semelhante àquelas encontradas no jogo.

Palavras-chave: Basquetebol; Esportes juvenis; Monitoramento.
1 Federal University of Juiz de Fora. Faculty of Physical Education and Sports. Juiz de Fora. MG. Brazil

Received: October 20, 2018 Accepted: March 25, 2019

How to cite this article Brandão FM, Ribeiro Junior DB, Cunha VF, Meireles GB, Bara Filho MG. Differences between training and game loads in young basketball players. Rev Bras Cineantropom Desempenho Hum 2019, 21:e59840. D0l: http://dx.doi. org/10.1590/1980-0037.2019v21e59840

Copyright: This work is licensed under a Creative Commons Attribution 4.0 International License. 


\section{INTRODUCTION}

Basketball is an invasion sports characterized by intermittent high-intensity actions (sprints, jumps, changes of direction) interspersed by low-intensity actions (walking and running) ${ }^{1}$. Coaches of collective sports such as basketball have the mission to provide several stimuli during training to optimize and / or maintain performance and to reduce negative adaptations (nonfunctional overreaching, lesions or diseases) ${ }^{2}$.

However, the great difficulty of collective sports coaches is to provide these stimuli from the same training, considering the individual characteristics of athletes ${ }^{3}$. In this sense, monitoring training loads is essential. From the external training load (ETL), it is possible to obtain data on the work performed by athletes such as number of jumps, distance traveled, number of weekly hours trained and others ${ }^{4}$.

However, only the ETL measure is not enough, since within a group of athletes, the same ETL can be perceived and assimilated with different magnitudes ${ }^{5}$. Thus, measuring the Internal Training Load (ITL) can provide data on the psychophysiological stress that was imposed on each athlete in response to the training stimulus (ETL). Based on the above, coaches can evaluate how the same training can generate several responses, either positive (adaptation or overcompensation) or negative (nonfunctional overreaching, lesions or diseases) ${ }^{6}$.

In this sense, the interaction between ETL and ITL can be compared to a dose-response relationship, in which the monitoring of both leads the coach to be more effective in the prescription of training to provide positive adaptations while reducing the chances of poor adaptations ${ }^{4}$.

Several methods are described in literature for measuring ETL and ITL responses ${ }^{4}$; however, not all methods are accessible in day-to-day training. Thus, using an integrated training monitoring system, using both ETL and ITL measures is practical and useful for coaches, since it is possible to perform a holistic and robust analysis of the dose-response relationship of training or competitions ${ }^{7}$.

Fox et al. ${ }^{7}$ reported that microsensors are viable alternative for the quantification of training and competition loads in basketball, since they simultaneously monitor internal loads (through integrated Heart Rate Measurement) and external loads.

A number of microsensors are currently available on the market, and this increase has occurred due to the rapid return of data, since some provide real-time monitoring instead of post-exercise evaluation of recorded data, providing easy and continuous monitoring throughout the season ${ }^{8}$. Thus, microsensors have become an accessible and valuable tool for coaches, especially of high-performance teams ${ }^{9}$.

However, the quantification of loads, both in training and in competitions for young athletes is fundamental to guarantee long sports career ${ }^{10}$. Evidence suggests that the relationship between high training volumes and injuries can lead to early retirement in young athletes ${ }^{2}$. In addition, Lupo 
et al. ${ }^{11}$ suggest that $\mathrm{U}-17$ basketball players are at the most crucial and complex stage to develop physical and tactical aspects, which strengthens the need for systematic monitoring of training loads in this population.

Nevertheless, surveys that use an integrated approach for the monitoring of training and competitions in young basketball players are scarce in literature ${ }^{7}$. The results of this study will allow basketball coaches working with young athletes to understand the need for the systematic monitoring of training loads so that they develop more accurate training approaches based on evidence. Therefore, the aim of this study was to compare training and game loads in young male basketball players.

\section{METHOD}

\section{Sample}

The study included 13 male athletes (age of $16.4 \pm 0.6$ years, height $177.5 \pm$ $6.1 \mathrm{~cm}$, body mass $70.9 \pm 9.0 \mathrm{~kg}$ and fat percentage $10.8 \pm 3,2 \%$ ), members of an under-17 basketball team part of the "Formação em basquetebol: Da base para a Ponta" extension project carried out at the Faculty of Physical Education and Sports - Federal University of Juiz de Fora.

The study was approved by the Human Ethics Research Committee of the Federal University of Juiz de Fora under CAAE No. 74111517.8.0000.5147. In addition, contact was established with the teacher responsible for the extension project. With the consent of the teacher, athletes were invited to participate in the study and informed about the possible risks and benefits involved. After invitation acceptance, all athletes and their parents / guardians signed the assent form and the Free and Informed Consent Form, respectively, agreeing with participation in the voluntary form.

\section{Instruments}

The monitoring system used was the Polar Team Pro equipment composed of three parts: 1) a set of 10 sensors; 2) a recharge base; and 3) a cloud-based player performance analysis software available on the iPad for real-time monitoring and connected web service for post-session analysis.

Polar Team Pro sensors weigh 39 grams and include a $10 \mathrm{~Hz}$ GPS and heart rate technology with beat-to-beat data recording. Indoor, GPS data are not available and all movement data are calculated from information provided by the Inertial Measurement Unit (IMU) consisting of acceleration sensors, gyroscope and magnetometer $(200 \mathrm{~Hz})$.

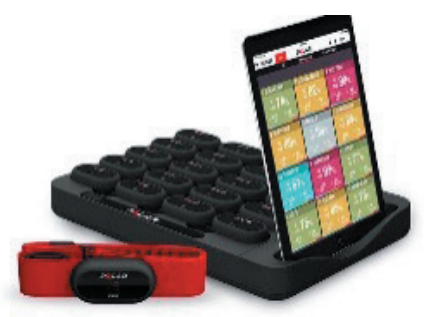

Figure 1. Polar Team Pro equipment 


\section{Procedures}

Athletes were familiar with instruments and procedures three weeks before the start of the investigation period. The anthropometric characteristics of participants were obtained before the beginning of the study. Body weight and body fat percentage were measured using a Balmak Actlife electronic digital scale, model slimtop-180, and height using a Sanny portable stadiometer model Compacto, with capacity of measuring up to 2 meters and 10 centimeters. Then, 4 training sessions and one game session were monitored, without any influence on the training planning and execution by researchers, totaling 49 individual sessions.

During training sessions, eight to ten athletes were randomly selected to undergo monitoring by using a sensor attached to a chest strap containing the Polar Team Pro equipment (Polar Team Pro, Polar Electro Oy, Kempele, Finland). This equipment was used both for measuring ETL data through the motion sensor and for HR-based ITL data. Information was transmitted in real time to an iPad (Apple iPad A1822, China) via Smart bluetooth. After each training session, sensors were placed in the Polar Team Pro station to load and synchronize data with the Polar Team Pro iPad application and Web service, and then exported and analyzed using Excel software (Microsoft Corporation, USA).

HR was recorded through a short-range telemetry HR transmitter at $1 \mathrm{~s}$ intervals (Polar Team Pro system, Polar Electro Oy, Kempele, Finland). The Edwards' TRIMP (eTRIMP) method $^{12}$ was used to monitor ITL. This method expresses the heart rate (HR) responses of athletes as percentages of their HR max. HR max was estimated using the formula: $[201.104-(0.326 \mathrm{x} \text { age })]^{13}$. In this sense, eTRIMP was calculated based on the time spent in five HR zones and multiplied by a zone-specific weighting factor: duration in zone 1 (50-59\% of HRmax) multiplied by 1 , duration in zone 2 (60-69\% HRmax) multiplied by 2 , duration in zone 3 (70-79\% HRmax) multiplied by 3, duration in zone 4 (80-89\% HRmax) multiplied by 4 and duration in zone 5 (90-100\% HRmax) multiplied by 5 , and these scores were later summed up ${ }^{12}$.

For the measurement of ETL variables, Polar Team Pro system was used, which presents a $200 \mathrm{~Hz}$ triaxial accelerometer and monitors distances and positions at frequency of $10 \mathrm{~Hz}$. From this, variable distance traveled was considered for data analysis.

The training of these athletes was performed three times a week and monitored sessions consisted of technical-tactical elements approached from the cognitive-situational methodology.

In relation to HR data recorded during the game, it is important to highlight that only the active playing time (player on the court) was analyzed, so intervals between quarters were not considered.

\section{Statistical analysis}

To observe differences between eTRIMP, HR max and distance traveled, the T-Test was used for paired samples with 5\% significance level. The version 20 of the SPSS software for Mac was used. 


\section{RESULTS}

The eTRIMP, HR max and distance traveled descriptive values are presented as mean \pm standard deviation in table 1 . Based on results, no statistically significant differences were found between the mean values of training sessions and the game session in relation to eTRIMP measures and distance traveled. However, HR max was significantly higher during the game compared to HR max during training.

Table 1. Edwards TRIMP data, maximum heart rate and total distance traveled for training and game sessions.

\begin{tabular}{lccc}
\hline & Training $(\mathrm{n}=4)$ & Game $(\mathrm{n}=1)$ & P-value \\
\hline eTRIMP (A.U.) & $132 \pm 69$ & $108 \pm 33$ & 0.44 \\
Mean HR max $(\mathrm{bpm})$ & $143 \pm 67$ & $199 \pm 4$ & $0.03^{*}$ \\
Total distance $(\mathrm{m})$ & $2.273 \pm 1170$ & $2.240 \pm 617$ & 0.94 \\
\hline
\end{tabular}

Note. ${ }^{*}$ Statistically significant $(p<0.05)$. A.U. = Arbitrary units.

\section{DISCUSSION}

Studies in literature comparing game and training demands in team sports with young athletes are scarce. In this sense, microsensors appear as an alternative for a more precise monitoring of game and training demands in collective sports. Montgomery, Pyne and Minahan ${ }^{9}$ demonstrated that the use of frequency and accelerometer can be valid measures to differentiate physical and physiological demands in basketball, both in training and competitions.

Thus, the results of the present study demonstrate that there was no difference between training loads and game loads in a team formed by young basketball players in relation to eTRIMP (ITL) and distance traveled (ETL) measurements, as can be seen in table 1. A study with semiprofessional basketball players found ITL values similar to those of the present study $(179 \pm 81)^{14}$. In this sense, it could be inferred that the training load values of the investigated team are close to values reported in international literature.

Regarding distance traveled, although training and game values did not present statistically significant differences, they were substantially lower than values reported by a youth basketball team that covered 7.558 $\pm 575 \mathrm{~m}$. However, the methodology used to analyze the distance traveled was different from that of the present study ${ }^{15}$.

Based on results, it was found that players were under greater internal pressure during the game, reporting HR max value of $199 \pm 4 \mathrm{bpm}$ compared to mean HR max value of $143 \pm 67 \mathrm{bpm}$ for training. Thus, only variable "HR max" showed statistically significant difference $(p=0.03)$ when training with game were compared. In a study of first-division players in the Spanish basketball league, the mean HR max value found during competitions was $198 \pm 9 \mathrm{bpm}^{16}$. 
In this sense, several factors can influence a game in relation to increased HR max values, such as duration, athletes' fitness, motivation, tactical strategy of teams and others ${ }^{15}$. In the present study, the increased HR max value found in the game can be explained by the fact that a real competition generates tension response greater than that in the training condition.

Another fact to be considered is that HR can overestimate the exercise intensity during the game due to the increased emotional tension found during competition ${ }^{17}$. Thus, these findings corroborate Australian basketball and soccer data, in which HR of games was substantially higher than HR of training ${ }^{9,18}$.

Thus, basketball coaches should consider the fact that games, friendly or competition, may present higher cardiovascular load compared to training ${ }^{16}$. This reflects the importance of training specificity to maximize athletes' performance during competition, mainly because there are factors that influence the cardiovascular response during training, such as number of players involved in an exercise, court size and even the number of interventions performed by coaches to correct moves or give instructions ${ }^{19,20}$.

As a study limitation, it could be emphasized that data are not separated by the position of players, since physiological demands may vary according to the position of the player and that an analysis according to position would be essential for better training individualization. Another limiting factor was the reduced number of game sessions.

\section{CONCLUSION}

It was concluded that microsensors are useful in monitoring ETL and ITL in young basketball players. In addition, loads applied during training were similar to those applied in the game, that is, athletes were prepared to withstand the loads applied. Although the results found may help basketball coaches with regard to the management of training and game loads in young athletes, further studies are needed to characterize the differences of game and training demands among young basketball players, considering a higher number of game sessions and the position of players.

\section{COMPLIANCE WITH ETHICAL STANDARDS}

\section{Funding}

This research did not receive any specific grant from funding agencies in the public, commercial, or not-profit sectors. This study was funded by the authors.

\section{Ethical approval}

Ethical approval was obtained from the local Human Research Ethics Committee - Federal University of Juiz de Fora and the protocol (No. 2.754.464) was written in accordance with standards set by the Declaration of Helsinki. 


\section{Conflict of interest statement}

The authors have no conflict of interests to declare.

\section{Author Contributions}

Conceived and designed the experiments: FMB; DBRJ; VFC; MGBF. Performed the experiments: FMB; VFC; GBM. Analyzed data: FMB; DBRJ. Contributed with reagents/materials/analysis tools: FMB; DBRJ; VFC; GBM; MGBF. Wrote the paper: FMB; DBRJ; VFC; MGBF.

\section{REFERENCES}

1. Rose Junior D, Tricoli V. Basquetebol: do treino ao jogo. Manole; 2017.

2. Bourdon P, Cardinale M. Monitoring Athlete Training Loads: Consensus Statement. J Sport 2017;12(2)161-170.

3. Manzi V, D’Ottavio S, Impellizzeri FM, Chaouachi A, Chamari K, Castagna C. Profile of Weekly Training Load in Elite Male Professional Basketball Players. J Strength Cond Res 2010; 24(5):399-406.

4. Borresen J, Lambert MI. The quantification of training load, effect on performance. Sport Med 2009;39(9):779-795.

5. Foster C, Florhaug JA, Franklin J, Gottschall L, Hrovatin LA, Parker S, et al. A new approach to monitoring exercise training. J Strength Cond Res 2001; 15(1):109-115.

6. Impellizzeri FM, Rampinini E, Coutts AJ, Sassi A, Marcora SM. Use of RPEbased training load in soccer. Med Sci Sports Exerc 2004; 36(6):1042-1047.

7. Fox JL, Scanlan AT, Stanton R. A Review of Player Monitoring Approaches in Basketball: Current Trends and Future Directions. J Strength Cond Res 2017;31(7):2021-2029.

8. Passfield L, Hopker JG. A Mine of Information: Can Sports Analytics Provide Wisdom From Your Data? Int J Sports Physiol Perform 2017; 12(7):1-17.

9. Montgomery PG, Pyne DB, Minahan CL. The physical and physiological demands of basketball training and competition. Int J Sports Physiol Perform 2010;5(1):75-86.

10. Murray A. Managing the Training Load in Adolescent Athletes Athlete Development: A Modern Phenomenon? Developing Athletes With Sound Scientific Principles. Int J Sports Physiol Perform 2017;12(2):42-49.

11. Lupo C, Tessitore A, Gasperi L, Gomez MAR. Session-RPE for quantifying the load of different youth basketball training sessions. Biol Sport 2017;34(1):11-17.

12. Edwards S. The Heart Rate Monitor Book. Medicine \& Science in sports \& Exercise; 1994.

13. Shargal E, Kislev-Cohen R, Zigel L, Epstein S, Pilz-Burstein R, Tenenbaum G. Age-related maximal heart rate: examination and refinement of prediction equations. J Sports Med Phys Fitness 2014; 55(10):1207-1218.

14. Scanlan AT, Wen N, Tucker PS, Borges NR, Dalbo VJ. Training Mode's Influence on the Relationships between Training-Load Models during Basketball Conditioning. Int J Sports Physiol Perform 2014; 9(5):851-856.

15. Ben Abdelkrim N, Castagna C, Jabri I, Battikh T, El Fazaa S, Ati J El. Activity Profile and Physiological Requirements of Junior Elite Basketball Players in Relation to Aerobic-Anaerobic Fitness. J Strength Cond Res 2010; 24(9):2330-2342.

16. Torres-Ronda L, Angel R, Llabres-Tores I, Ias HB, Schelling AX. Positiondependent cardiovascular response and time-motion analysis during training drills and friendly matches in elite male basketball players. J Strength Cond Res 2016;30(1):60-70. 
17. Bangsbo J, Mohr M, Krustrup P. Physical and metabolic demands of training and match-play in the elite football player. J Sports Sci 2006; 24(7):665-674.

18. Henderson B, Cook J, Kidgell DJ, Gastin PB. Game and Training Load Differences in Elite Junior Australian Football. J Sports Sci Med 2015;14(3):494-500.

19. Carlo C, Impellizzeri FM, Chaouachi A, Nidhal BA, Manzi V. Physiological responses to ball-drills in regional level male basketball players. J Sports Sci 2011;29(12):1329-1336.

20. Schelling X, Torres L. Accelerometer load profiles for basketball-specific drills in elite players. J Sport Sci Med 2016;15(4):585-591.

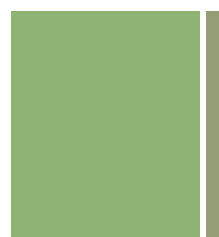

Corresponding author

Fernanda Martins Brandão

Federal University of Juiz de Fora.

Faculty of Physical Education and Sports.

Campus Universitário, s/n, Martelos.

CEP 36036-900 - Juiz de Fora - MG - Brazil.

email: fernandamabrandao@gmail.com 